\title{
Effects of different methods of antagonist muscles pre-activation on knee extensors neuromuscular responses
}

\author{
Efeitos da ordem de pré-ativação dos músculos antagonistas nas respostas \\ neuromusculares dos extensores do joelho
}

Rodrigo L. Carregaro 1,3, Rafael R. Cunha ${ }^{3}$, Jefferson R. Cardoso², Ronei S. Pinto ${ }^{4}$, Martim Bottaro 3

\begin{abstract}
Background: Pre-activation of antagonistic muscles is used in different modalities of exercise and neuromuscular rehabilitation protocols, but its effectiveness is still controversial. Objective: To verify the impact of two different methods of pre-activation of knee antagonist muscles in the neuromuscular performance and electromyographic activity of knee extensors. Methods: Fifteen healthy men $(23.9 \pm 4.2$ years of age, $1.78 \pm 0.08$ meters and $81.4 \pm 10.7 \mathrm{~kg}$ ) performed, on different days, two protocols of isokinetic muscle contraction with 4 sets of 10 repetitions at $60^{\circ} . \mathrm{s}^{-1}$ and 1 minute between sets: (1) Reciprocal Contraction (RC): reciprocal concentric exercise of agonist/antagonist muscles (knee flexion [KF] immediately followed by knee extension [KE]) and (2) Superset (SS): alternated concentric exercise of agonist/ antagonist muscles (KF set followed by a set of KE). A repeated measures ANOVA with least-significant difference post-hoc test was used to detect differences between protocols. Results: There were no significant differences between protocols $(p>0.05)$ for peak torque (PT) and total work (Tw). On the SS protocol there was a significant decrease in Tw on the last two sets $(p<0.05)$ while for RC the decrease occurred only in the last set. There were no significant differences of root mean square (RMS) between protocols, but the activation pattern was more uniform during the RC protocol. Conclusion: The results indicated that the peak torque was not influenced by the different preactivation methods. However, the RC protocol appears to better maintain the total work training volume.
\end{abstract}

Keywords: electromyography; resistance training; dynamometer; muscle strength; rehabilitation; movement.

\section{Resumo}

Contextualização: A pré-ativação de músculos antagonistas é utilizada em diferentes modalidades de exercício e em diferentes protocolos de reabilitação neuromuscular, porém suas respostas ainda são controversas. Objetivo: Verificar o impacto de duas diferentes estratégias de pré-ativação de músculos antagonistas no desempenho neuromuscular e na atividade eletromiográfica dos extensores do joelho. Métodos: Quinze homens sadios $(23,9 \pm 4,2$ anos; $1,78 \pm 0,08 \mathrm{~m}$ e 81,4 $\pm 10,7 \mathrm{~kg}$ ) realizaram, em dias distintos, dois protocolos de ações musculares isocinéticas com quatro séries de dez repetições a $60^{\circ} . \mathrm{s}^{-1}$ e intervalo de 1 minuto entre séries: 1) contração recíproca (CR): exercício concêntrico recíproco de antagonistas/agonistas (uma repetição de flexão do joelho [FJ] imediatamente seguida por uma de extensão do joelho [EJ]) e 2) supersérie (SS): exercício concêntrico alternado dos antagonistas/agonistas (dez repetições de FJ seguidas por dez de EJ). Utilizou-se a ANOVA para medidas repetidas com teste post-hoc LSD (Least-significant diference) para verificar a diferença entre protocolos. Resultados: Não houve diferença significante $(p>0,05)$ entre protocolos para o pico de torque (PT) e trabalho total (Tt). Em relação ao Tt, o protocolo SS apresentou quedas significantes nas duas últimas séries $(p<0,05)$ enquanto, no $C R$, a queda ocorreu apenas na última série de exercício. Não houve diferenças no Root Mean Square (RMS) entre protocolos, mas o padrão de ativação foi mais uniforme durante o CR. Conclusão: Os resultados indicaram que a queda na força muscular não é influenciada pelas diferentes formas de pré-ativação da musculatura antagonista, no entanto parece que a utilização de CR permite uma melhor manutenção do volume de treinamento.

Palavras-chave: eletromiografia; treinamento de resistência; dinamômetro; força muscular; reabilitação; movimento.

Received: 02/10/2011 - Revised: 06/28/2011 - Accepted: 07/10/2011

${ }^{1}$ Course of Physical Therapy, Universidade Federal de Mato Grosso do Sul (UFMS), Campo Grande, MS, Brazil

${ }^{2}$ Physical Therapy Department, Universidade Estadual de Londrina (UEL), Londrina, PR, Brazil

${ }^{3}$ Faculty of Physical Education, Universidade de Brasília (UnB), Brasília, DF, Brazil

${ }^{4}$ School of Physical Education, Universidade Federal do Rio Grande do Sul (UFRGS), Porto Alegre, RS, Brazil

Correspondence to: Rodrigo Luiz Carregaro, CCBS/Curso de Fisioterapia, Unidade XII, Av. Costa e Silva, S/Nº, Campus Universitário UFMS, Cidade Universitária, CEP 79070-900, Campo

Grande, MS, Brasil, e-mail: rodrigocarregaro@yahoo.com.br 


\section{Introduction $: \because 8$}

Resistance exercise are considered an essential element in rehabilitation programs and physical conditioning ${ }^{1,2}$. Programs that involve resistance exercises can also focus on the prevention of injuries ${ }^{3,4}$, such as in cases where joint instability generated by deficiency of the dynamic joint stabilizers predisposes to degeneration of synovial structures ${ }^{5}$.

Strength gains provided by resistance exercise programs are associated with important clinical benefit, and therefore, numerous methods of resistance training have been developed ${ }^{6,7}$. Recently, the use of pre-activation of antagonist muscles before activation of the agonists has received increasing attention in rehabilitation clinics and gyms. According to Júnior et al. ${ }^{8}$, a goal pursued by professionals that employ resistance exercise for performance and rehabilitation is to link muscle actions so that the sequence of stimuli provides an effective muscle response. The characteristics of pre-activation of antagonistic muscles seem to positively influence the generation of agonists' strength. Therefore, individuals performing these pre-activation exercises could potentially improve their motor performance and generate higher strength levels. However, evidence to support the use of pre-activation exercises are still scarce and controversial.

Among the types of agonists pre-activation, we can highlight the methods known as superset $(\mathrm{SS})^{9-13}$ and reciprocal contractions $(\mathrm{RCs})^{14-19}$. The findings concerning the effectiveness of these protocols are controversial and methodological variations makes it difficult to compare the benefits of both forms of exercises. Burke, Pelham and Holt ${ }^{9}$ found that the SS protocol has positive effects on strength generation of the agonist; however this was not the case when the pre-activation of the antagonist was performed by means of simple sets and with maximal and prolonged contractions ${ }^{10}$. Additionally, Bohannon, Gibson and Larkin ${ }^{15}$ showed no difference in strength between the RC method and a traditional method (without pre-activation of the antagonist) in healthy subjects. On the other hand, other studies have shown benefits of $\mathrm{RC}^{16,17,19}$, but the conclusions were based on exercises conducted with simple series, ie, only one set (defined as a group of repetitions developed continuously, without interruption) although resistance exercises are most commonly based on more than one set (multiple sets).

In one of the few studies that compared the two methods, Bohannon ${ }^{14}$ showed a torque $10 \%$ higher during the RC protocol compared to SS in participants with a history of stroke. In a recent study, Carregaro et al..$^{20}$ reported no significant differences in torque production of the agonist, but found that RC leads to greater work capacity than the SS. It is important to note that most of the studies cited did not use surface electromyography (EMG) to evaluate the differences between the modalities, and to date, few studies have evaluated muscle activation ${ }^{10,13,18,19}$. Moreover, with the exception of Robbins et al. ${ }^{13}$, all studies have focused on understanding the effects of different execution speeds in strength generation, making it difficult to compare performance between the modalities. Thus, the objective of this study was to evaluate the impact of two different pre-activation methods of knee flexor muscles in the generation of torque, work and electromyographic activation of the Vastus Medialis muscle (VM) during knee extension exercises (KE).

\section{Methods $: \because$.}

\section{Sample}

Fifteen healthy men $(23.9 \pm 4.2$ years of age; $1.78 \pm 0.08$ meters and $81.4 \pm 10.7 \mathrm{~kg}$ ) participated in the study. They were instructed not to perform any kind of strenuous physical activity for the lower limbs during the study period. Inclusion criteria were age between 18 and 35 years and be physically active (engaged in some kind of physical exercise, at least twice a week). Subjects were excluded if they had a history of trauma and any type of musculoskeletal surgery in the lower limbs and spine, cardiovascular disease and diagnosed arterial hypertension. All individuals who participated were informed about the research objectives and procedures and were invited to participate in the study duly approved by the Ethics Committee of the Faculty of Health of the Universidade de Brasília (FS/UnB), Brasília, DF, Brazil (protocol nº. 161/2008), signing an informed consent, in accordance with Resolution 196 of the CNS.

\section{Evaluation procedures}

Participants attended the Laboratory of Strength Training in three different occasions, with a minimum interval of 72 hours between each visit. On the first day, participants familiarized themselves with the exercise protocols and performed two sets of four maximal repetitions at $60^{\circ} . \mathrm{s}^{-1}$ (in each protocol), with 1 minute interval between sets. Between the protocols, there was a period of 5 minutes of rest. A familiarization of the maximal voluntary isometric contraction (MVIC) was also performed, in which all patients performed two maximal contractions of 5 seconds, with an interval of 2 minutes between them.

On the second and third visits participants performed the exercise protocols, with four sets of ten repetitions each and speed of $60^{\circ} . \mathrm{s}^{-1}$, in the dominant limb (leg used to kick a ball). Between sets, there was a rest interval of 1 minute ${ }^{21}$. The 
protocols used were: 1) RC (four series of reciprocal concentric exercise of antagonists and agonists, characterized by the movement of knee flexion (KF) immediately followed by knee extension (KE) in each repetition) and 2) SS (four sets of exercise in alternate mode of antagonists and agonists, each set was characterized by ten concentric repetitions of KF with passive $\mathrm{KE}$ followed immediately by a set of ten concentric repetitions of KE with passive KF). In the 24 hours preceding the meetings, participants were instructed not to perform strenuous exercise and not to drink energy drinks. The order of the two protocols was randomized.

During the evaluations, participants were asked to position their arms against the chest, so that the arms did influence the strength generation ${ }^{22}$. In addition, participants were instructed to perform the movements with maximum strength throughout the full available range of motion. Before performing the procedures and exercises on the dynamometer, all subjects underwent a 10 minutes warm up session on a stationary bike with no load. Verbal encouragement and visual feedback using the computer screen were given in an attempt to achieve the maximum level of effort. All procedures were performed by the same investigator.

\section{Isokinetic Dynamometer}

An isokinetic dynamometer Biodex System 3 (Biodex Medical, Shirley, NY.) was used. Calibration was performed according to the specifications of the manufacturer's manual, and the gravity correction was obtained through measuring the torque exerted by the resistance arm and the leg of subject (relaxed) in the position of terminal knee extension. Each subject was positioned on the chair allowing for a free and comfortable movement of knee flexion and extension (Figure 1). To prevent movements of knee hyperextension, a range of motion of $80^{\circ}$ flexion/extension (excursion between $10^{\circ}$ and $90^{\circ}$, considering $0^{\circ}$ the full knee extension) was used. The hip position was standardized at $100^{\circ}$ of flexion (position of the chair) for all subjects. The lateral epicondyle of the femur was used as reference point for the knee rotation axis and used for aligning with the rotation axis of the device. The height of the chair, the backrest tilt, the height of the dynamometer and the adjustment of the resistance arm were recorded and replicated each day to guarantee standardization between sessions.

\section{Surface electromyography}

The recording and processing of electromyographic signals were based on the recommendations of the International Society of Electrophysiology and Kinesiology ${ }^{23}$ and of Soderberg and Knutson ${ }^{24}$. The placement of the electrodes was based on the guidelines of the project SENIAM (Surface Electromyography for the Non-Invasive Assessment of Muscles) $)^{25}$.

A portable surface electromyography of four channels (Miotool, Miotec Equipamentos Biomédicos Ltda, Brazil), with 14 bits resolution, noise level <2LSB and common mode rejection of $110 \mathrm{db}$ was used. The channels were fitted with a sampling of $2000 \mathrm{~Hz}$, and a final gain of 1000 times. The simple differential active electrodes (input impedance of $10^{10} \mathrm{Ohm}$ ) had polyethylene foam with hypoallergenic medical adhesive, solid stick gel, bipolar contact of $\mathrm{Ag} / \mathrm{AgCl}$ and distance between the poles of $20 \mathrm{~mm}$. The muscle evaluated was the VM, and the reference electrode was attached to the bony prominence of the seventh cervical vertebra (C7). The VM muscle was chosen based on the study of Miller, Croce and Hutchins ${ }^{18}$, that found that the VM had 1.5 times greater activation than the other muscles during a similar protocol to that used in the present study.

The electrode was positioned over the belly of the VM muscle and parallel to the muscle fibers ${ }^{26}$ (Figure 1). Before placing the electrodes, the area was shaved and light abrasion with $70 \%$ alcohol was performed. The placement of the electrodes was identified on the first day of testing and a high setting pen mark was made on the skin to ensure that the same position was used on the subsequent days.

On the second and third visits all subjects performed a MVIC with knee joint positioned at $60^{\circ}$ (having as reference for $0^{\circ}$ the full knee extension). The MVIC was characterized by two contractions of 5 seconds each, with interval of 2 minutes of rest between them. After 5 minutes of rest, subjects were instructed to start the exercise protocols.

The electromyography analysis was conducted on the Miograph 2.0 program (Miotec Equipamentos Biomédicos Ltda,

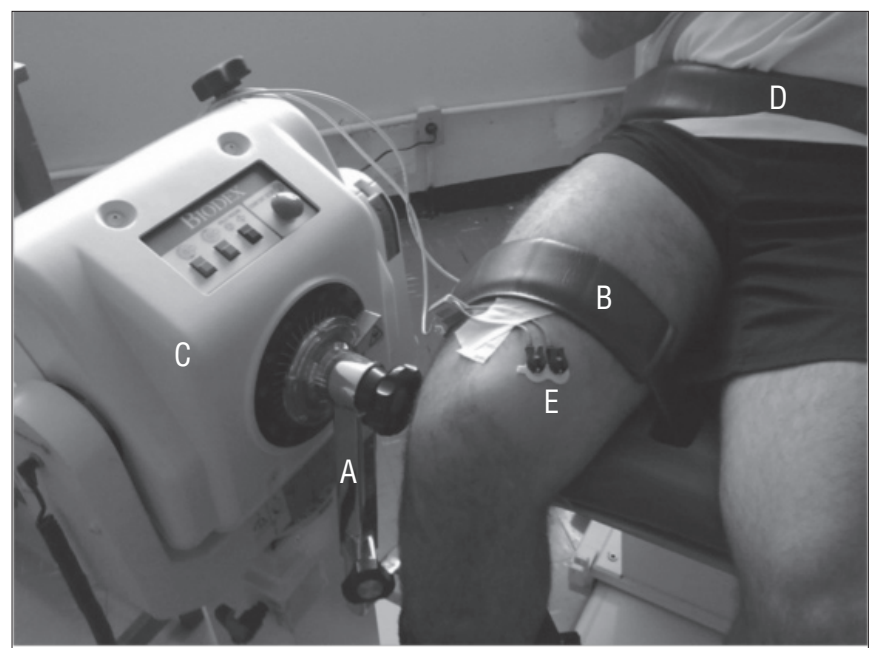

A) Lever arm; B) Thigh strap; C) Dynamometer; D) Waist strap; E) Electrode on VM muscle.

Figure 1. Experiment illustration on the isokinetic dynamometer. 
Brazil). The electromyographic signal was filtered with a band-pass frequency between $20 \mathrm{~Hz}$ and $450 \mathrm{~Hz}$ (Butterworth filter of 4th order) and was normalized using the MVIC. In the normalization procedure, the repetition of the MVIC with the higher Root Mean Square (RMS) value was used as reference, considering the central 3 seconds of the signal. To analyze the pattern of electromyographic activation of the VM muscle in the protocols, the mean RMS of the first three and last three repetitions in each set of exercise was used.

\section{Data analysis}

The SPSS program (Statistical Package for Social Sciences), version 13.0, was used for all statistical analysis. The data are shown as mean \pm standard deviation; the normality of data was checked using the Shapiro-Wilk test. The dependent variables analyzed were peak torque (PT), total work (Tw) and RMS (displayed as \% of MVIC). The Analysis of Variance (ANOVA) $2 \times 4$ for repeated measures [protocols (RC and SS) x number of sets (1st, 2nd, 3rd, 4th)], with post-hoc least-significant difference (LSD) test was used for the PT and Tw variables. For the RMS, an ANOVA 2 x 4 x 6 for repeated measures [protocols ( $\mathrm{RC}$ and SS) $x$ number of sets (1st, 2nd, 3rd, 4th) x repetitions (1st, 2nd, 3rd, 8th, 9th, 10th)] was conducted. The Mauchly's W sphericity test was conducted and when rejected, the analysis was always based on the Greenhouse-Geisser correction. The significance adopted was $5 \%(p<0.05)$.

\section{Results $\because:$.}

The values of PT and Tw generated during the execution of the RC and SS protocols are shown in Table 1. The comparison between the protocols showed no significant difference for PT and $\operatorname{Tw}(p>0.05)$.

In the intragroup analysis, there was a significant decrease in the strength generated in the last set of exercise for both protocols $(p<0.05$ - Table 1$)$. However, despite the absence of statistical significance between the protocols, it is possible to notice that the RC protocol showed lower percentages of decrease $(2 \%, 5 \%$ and $10 \%$ in sets two, three and four) in relation to the SS protocol (3\%, $7 \%$ and $14 \%$ in sets two, three and four), when compared with the first set of exercise. In relation to Tw, the SS protocol showed differences in exercise volume characterized by significant decreases in the last two sets $(p<0.05)$. For the RC protocol, the decrease occurred only in the last set $(p<0.05)$. Despite the lack of differences between protocols, the decrease in work in the last set reached $22 \%$ in SS, against a decrease of $14 \%$ in $\mathrm{RC}$.

The findings relating to the RMS of the VM muscle are shown in Table 2 . There was no statistically significant difference between the protocols and the sets over the analyzed repetitions $(p>0.05)$. It is possible to notice that the SS protocol showed significant variations $(p<0.05)$ both in the initial and in the final phase, for all series, indicating increase in the activation of the VM muscle. The increases of activation were also significant in the $\mathrm{RC}(p<0.05)$, but concentrated in the first two repetitions and maintaned until the end. There was a significant interaction between protocols and repetitions $(p<0.05)$, which may indicate specific electromyographic patterns of the protocols, as illustrated in Figure 2.

\section{Discussion $\because \because$.}

The present study hypothesized that different protocols of pre-activation of knee flexor muscles (antagonists) influence the ability to generate strength and work of the extensors (agonists). The comparison between the modalities showed that both provide similar rates of generation of extensor strength. However, it appears that the RC method provides greater capacity of work. The RC method showed, qualitatively, a curve with a more uniform distribution between sets of exercise, when compared to the SS. In addition, the RC showed a stronger increase of the RMS, especially in the initial phases, which may represent more efficient muscle recruitment.

In this study, we found no significant differences of knee extensor torque between the protocols which differs from the results of Maynard and Ebben ${ }^{10}$, who found differences in knee extensor torque after a set of five maximal repetitions of exercise in the SS modality at $60^{\circ} . \mathrm{S}^{-1}$. In this study, the torque generated in the SS condition was approximately $4 \%$ lower than the control (KE exercise without pre-activation of agonist). This lower strength production may be attributed to an increase in co-activation of the flexor muscles, previously fatigued. However, comparisons with the study of Maynard and Ebben ${ }^{10}$ are

Table 1. Values of knee extensor peak torque and total work (mean \pm standard deviation).

\begin{tabular}{lcccccccc} 
& \multicolumn{3}{c}{ Knee extensor Peak Torque (N.m) } & \multicolumn{4}{c}{ Total Work (J) } \\
& Set 1 & Set 2 & Set 3 & Set 4 & Set 1 & Set 2 & Set 3 & Set 4 \\
\hline SS & $264.1 \pm 49.1$ & $254.9 \pm 52.7$ & $246.0 \pm 50.2$ & $228.3 \pm 41.5^{\star}$ & $2270.6 \pm 385.2$ & $2104.3 \pm 347.4$ & $1935.5 \pm 389.6^{*}$ & $1779.4 \pm 308.9^{*} \#$ \\
\hline RC & $261.4 \pm 37.0$ & $257.1 \pm 37.2$ & $248.3 \pm 37.3$ & $234.1 \pm 32.3^{*}$ & $2262.7 \pm 327.6$ & $2173.7 \pm 321.6$ & $2052.9 \pm 295.5$ & $1943.5 \pm 264.9^{*}$ \\
\hline
\end{tabular}

Less than Set 1: * $(p<0.05)$; Less than Set 2: \# $(p<0.05)$. RC=reciprocal contraction; SS=superset 
limited by the fact that they used simple sets and compared the SS with another modality of exercise. Another aspect was the absence of a period of familiarization to the SS protocol. On the other hand, Baker and Newton ${ }^{11}$ reported increases in the ability to generate power after an intervention with a set of eight repetitions (seated rowing exercise like SS). In this case, Baker and Newton ${ }^{11}$ explained the gains in power as an increase in the firing rate of the agonist muscles, caused by a neural stimulation influenced by a previous contraction of the antagonists (called post-tetanic potentiation). Although the study ${ }^{11}$ evaluated the variable power and upper limb muscles (which may have a different specificity than that of the lower limb muscles), it is possible that the same neural strategy occurred in our study and therefore, could explain the same performance and electromyography activation of the CR and SS modalities.

It is noteworthy that, in the present study, there was a decrease of $14 \%$ on the last set of torque in the SS condiction, while, in the $\mathrm{RC}$ condition, the decrease was smaller (10\%). Despite the lack of significance, this is an important practical observation, because a $4 \%$ difference between the protocols may represent benefits for an athlete or individual who is in process of rehabilitation and needs strength to carry a specific activity. In fact, Roy et al. ${ }^{17}$ suggested that the advantages stemming from reciprocal actions are due to facilitatory stimulation of the Golgi tendon organs (GTOs) of the flexor muscle and muscles spindles of extensors muscle, assigned to prior flexion. Their findings show that the reciprocal modality tends to generate a greater torque of the knee extensors, which would explain lower decrease in the RC condition. Apparently, such response would be explained by a neuromuscular event caused by the action of the flexor muscle, which would activate the GTOs and their motoneurons network, while, at the same time, the muscle spindles of the extensors (elongated) would facilitate and increase performance in the thereafter contraction. Kisner and Colby ${ }^{3}$ also suggested that during a concentric activation of the agonist, the antagonist has a reciprocal inhibition that allows its relaxation and, consequently, may facilitate the action of the agonist. This response may represent benefits during the performance of exercises with multiple sets, in the sense that the reciprocal inhibition may decrease the susceptibility to muscle fatigue over the repetitions and promote the maintenance of adequate levels of torque and work during the exercise session. However, this hypothesis must be confirmed by acute and chronic studies (longitudinal) through the use of indices based on the calculation of spectral moments, appropriate to monitoring the fatigue during dynamic muscle contractions ${ }^{27}$.

Despite the lack of statistical difference between protocols, the work generated by the RC showed higher values when compared to SS, especially in the last two sets. In turn, the intra protocols analysis showed that the RC performance was better, ie, had smaller decreases of work, unlike the SS. The decrease rates of RC and SS found in the last two sets (5\% and 14\%; 7\% and $22 \%$, respectively) showed that the work generated by two categories of resistance exercise in controlled conditions of speed, intensity and sets may impose important outcomes in training. Such findings points to the practical implications highlighted by Munn et al. ${ }^{28}$ and Kelly et al. ${ }^{29}$, who argued that increases in work capacity can determine important strength gains during resistance exercise. Exercise programs should be dynamic to induce physiological responses and performance gains, and research should incorporate other variables and not just the effects of simple and multiple sets ${ }^{30}$, aspect much discussed in the literature ${ }^{28-32}$. Tran and Docherty ${ }^{33}$ showed that the volume can also be expressed by the multiplication of repetitions and load used and also by the time under tension during muscle contraction. The longer the time under tension, the greater the deleterious effects on the excitation-contraction process of muscle fibers and, therefore, the greater the intensity of peripheral fatigue ${ }^{33}$. Although it was not measured in our study, it is possible that in the RC protocol, the extensor group has not been exposed so intensely (as the SS) to factors related to peripheral muscle fatigue, which could explain the greater work decrease (interpreted as the ability to generate strength by a specific distance) in the SS protocol.

In this study, there were no differences in RMS values between protocols, partially corroborating Robbins et al. ${ }^{13}$, who found no

Table 2. Root mean square (RMS) values (presented as \% MVIC) of 4 sets of each exercise protocol (RC: Reciprocal contraction; SS: Superset), (data presented as mean \pm standard deviation; Rep: Repetition).

\begin{tabular}{|c|c|c|c|c|c|c|c|}
\hline & & Rep1 & Rep2 & Rep3 & Rep8 & Rep9 & Rep10 \\
\hline \multirow{2}{*}{ Set 1} & SS & $81.6 \pm 12.6$ & $96.4 \pm 26.7^{*}$ & $100.3 \pm 20.4 \dagger$ & $113.5 \pm 20.8 \neq$ & $107.3 \pm 18.2 \#$ & $105.4 \pm 22.7$ \\
\hline & $\mathrm{RC}$ & $89.9 \pm 19.5$ & $102.2 \pm 25.6^{*}$ & $114.1 \pm 23.5 \dagger$ & $108.8 \pm 23.2$ & $112.9 \pm 24.7$ & $106.0 \pm 18.3$ \\
\hline \multirow{2}{*}{ Set 2} & SS & $79.4 \pm 15.8$ & $94.4 \pm 21.5^{*}$ & $93.8 \pm 19.3 \dagger$ & $112.4 \pm 25.1 \ddagger$ & $111.2 \pm 27.7 \#$ & $103.8 \pm 21.6$ \\
\hline & $\mathrm{RC}$ & $85.0 \pm 18.9$ & $94.2 \pm 20.2^{*}$ & $106.3 \pm 19.4 \dagger$ & $109.3 \pm 21.8$ & $108.1 \pm 20.7$ & $109.3 \pm 27.0$ \\
\hline \multirow{2}{*}{ Set 3} & SS & $85.6 \pm 16.1$ & $92.3 \pm 18.9^{*}$ & $96.0 \pm 14.9 \dagger$ & $104.2 \pm 25.97$ & $102.7 \pm 19.5 \#$ & $96.6 \pm 17.5$ \\
\hline & $\mathrm{RC}$ & $90.7 \pm 24.6$ & $101.8 \pm 21.1^{*}$ & $107.3 \pm 24.6 \dagger$ & $107.4 \pm 23.2$ & $109.5 \pm 23.3$ & $102.9 \pm 24.8$ \\
\hline \multirow{2}{*}{ Set 4} & SS & $91.5 \pm 19.5$ & $93.7 \pm 17.2^{*}$ & $100.2 \pm 14.3 \dagger$ & $110.3 \pm 23.3 \neq$ & $104.1 \pm 17.9 \#$ & $104.2 \pm 14.3$ \\
\hline & $\mathrm{RC}$ & $86.8 \pm 23.4$ & $100.4 \pm 22.2^{*}$ & $106.9 \pm 21.5 \dagger$ & $106.7 \pm 20.8$ & $105.4 \pm 19.7$ & $99.8 \pm 23.5$ \\
\hline
\end{tabular}

Significant differences: *Rep1 $\rightarrow \operatorname{Rep} 2: \mathrm{p}=0.003$; + Rep2 $\rightarrow \operatorname{Rep} 3: \mathrm{p}=0.006 ; \neq \operatorname{Rep3} \rightarrow \operatorname{Rep} 8: \mathrm{p}=0.000 ;$ \#Rep8 $\rightarrow \operatorname{Rep} 9: \mathrm{p}=0.03$. 


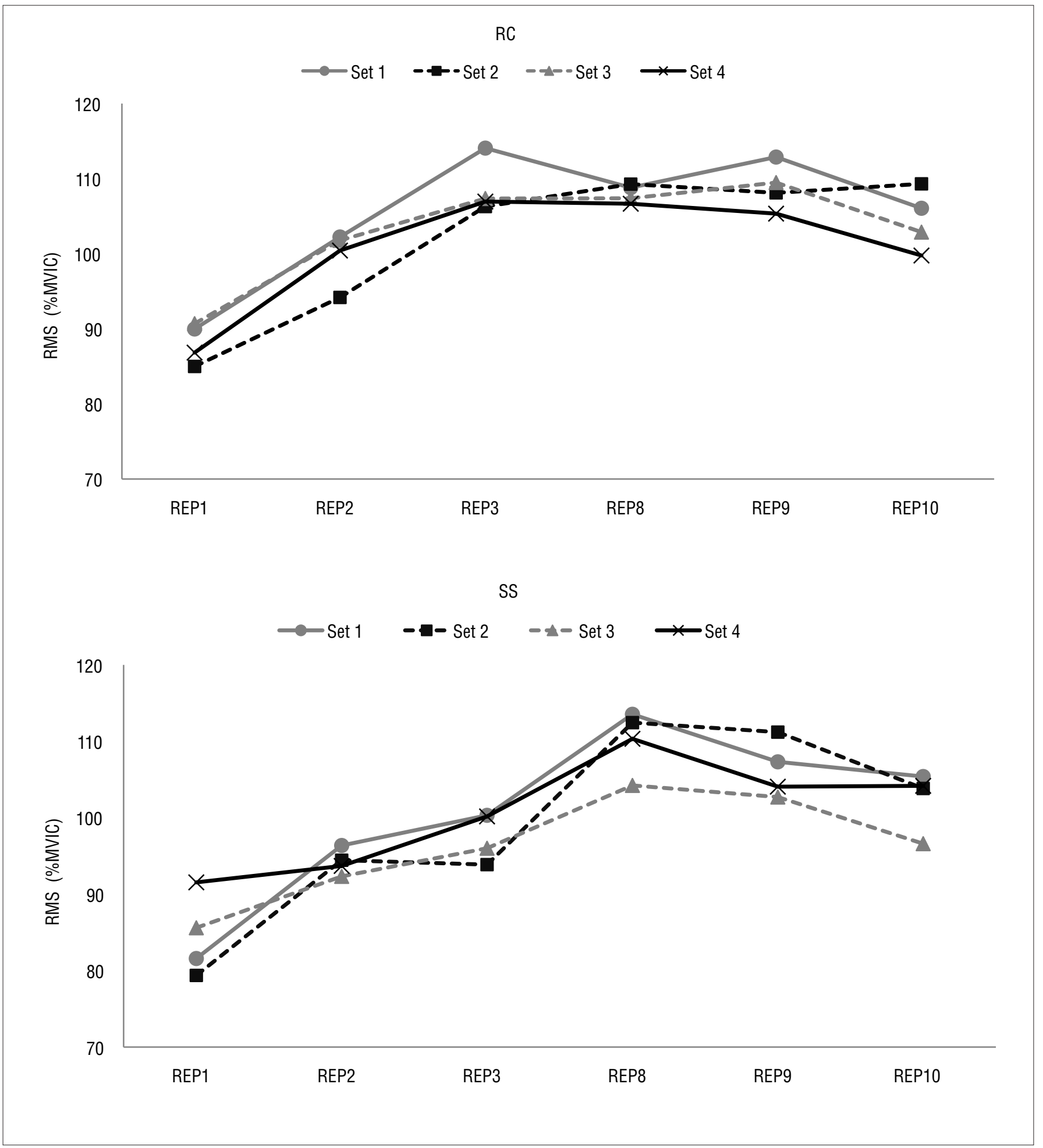

Figure 2. Temporal series with electromyography activation patterns (RMS in \% MVIC) over the exercise repetitions (REP) for protocols RC (reciprocal contraction) and SS (superset).

differences in electromyography activation between the SS and a traditional method during an exercise with three series. Coburn et al. ${ }^{34}$ while applying a training of just three sessions with a traditional protocol of KE exercise (four sets of ten repetitions at $30^{\circ} . \mathrm{s}^{-1}$ and $\left.270^{\circ} . \mathrm{s}^{-1}\right)$ also found no difference in RMS post-training, which is an argument about the lack of difference between the categories in our study. It is common consensus in the literature that the electromyographic signal amplitude is related to activation of motor units, and the frequency domain reflects the conduction speed of the contraction potential ${ }^{24,35}$, characterizing the EMG as an important tool to evaluate the neural adaptations after exercise. In the classic study by Moritani and deVries ${ }^{36}$, 
increases in the amplitude of the electromyographic signal after two weeks of training were found, demonstrating that neural effects were responsible for increases in strength in the initial phase. The findings of Moritani and deVries ${ }^{36}$ and Coburn et al. ${ }^{34}$ suggests that perhaps the acute nature of our study was not sufficient to determine differences between the RC and SS modalities. However, the significant interaction between protocols and repetitions, coupled with the visual standard of curves, showed evidences that, in the initial third of the exercise, the RC category provided a more intense activation; that remained until the end. It is noteworthy that one of the limitations of this study was the non-evaluation of co-activation of antagonist muscles. Another limitation is the lack of a control group to better understand the neuromuscular responses of the knee extensors without a prior pre-load of the antagonists.

Among the clinical applications of the protocols, it is possible to highlight the increased stability of the knee trough the strengthening of agonists and antagonists muscles ${ }^{37}$. The antagonist muscles provide control of mechanical forces that cause joint instability that is generated during the action of the agonists, showing that the strengthening of the antagonist muscle groups can restore or increase muscular balance in a joint $^{38}$. Thus, the $\mathrm{RC}$ and SS modalities involve reducing the risk of injuries while generating greater joint stability and, at the same time, promoting gains of muscle strength ${ }^{39}$. In this sense, it is recommended that physical therapists and sports professionals include, in their strategies for treatment/training, resistance exercises with alternate or reciprocal actions. Such strategies may influence neuromuscular skills necessary for activities that require motor control of prime muscles and knee stabilizers ${ }^{3}$, help prevent joint imbalances ${ }^{40}$ and dynamic stability in cases of anterior cruciate ligament deficiency ${ }^{37}$ Therefore, it is suggested that longitudinal studies to better determine possible adaptations resulting from the RC and SS protocols are conducted. Then, it will be possible to elucidate which modalityis most effective for strength gains and muscle performance in different populations.

\section{Acknowledgments $\because:$.}

To the Fundação de Apoio à Pesquisa do Distrito Federal (FAPDF), process nº. 2009/00212-2, and to the Conselho Nacional de Desenvolvimento Científico e Tecnológico (CNPq) - (processes $n^{\circ}$. 306114/2009-7 and 474740/2009-9 No) for financial support.

\section{References $: \because$.}

1. Ratamess NA, Alvar BA, Evetoch TK, Housh TJ, Kibler WB, Kraemer WJ, et al. Progression models in resistance training for healthy adults. Med Sci Sports Exerc. 2009;41(3):687-708.

2. ACSM. American College of Sports Medicine (ACSM). Diretrizes do ACSM para os testes de esforço e sua prescrição. $7^{\text {a }}$ ed. Rio de Janeiro: Guanabara Koogan; 2007.

3. Kisner C, Colby LA. Therapeutic exercise. Foundations and techniques. $5^{\text {th }}$ ed. Philadelphia: Davis Company; 2007.

4. Warburton DE, Nicol CW, Bredin SS. Prescribing exercise as preventive therapy. CMAJ. 2006;174(7):961-74

5. Traete RF, Pinto KNZ, Mattiello-Rosa SM. Relação entre a lesão condral e o pico de torque após reconstrução do ligamento cruzado anterior do joelho: estudo de casos. Rev Bras Fisioter. 2007;11(3):239-43

6. Fleck SJ, Kraemer WJ. Fundamentos do treinamento de força muscular. $3^{\text {a }}$ ed. Porto Alegre: Artmed; 2006

7. Gentil P, Oliveira E, Fontana K, Molina G, Oliveira RJ, Bottaro M. Efeitos agudos de vários métodos de treinamento de força no lactato sanguíneo e características de cargas em homens treinados recreacionalmente. Rev Bras Med Esporte. 2006;12(6):303-7.

8. Júnior VAR, Bottaro M, Pereira MCC, Andrade MM, Júnior PRWP, Carmo JC. Análise eletromiográfica da pré-ativação muscular induzida por exercício monoarticular. Rev Bras Fisioter. 2010;14(2):158-65

9. Burke DG, Pelham TW, Holt LE. The influence of varied resistance and speed of concentric antagonistic contractions on subsequent concentric agonistic efforts. J Strength Cond Res. 1999;13(3):193-7.

10. MaynardJ, Ebben WP. The effects of antagonist prefatigue on agonist torque and electromyography. J Strength Cond Res. 2003;17(3):469-74.

11. Baker D, Newton RU. Acute effect on power output of alternating an agonist and antagonist muscle exercise during complex training. J Strength Cond Res. 2005;19(1):202-5.

12. Kelleher AR, Hackney KJ, Fairchild TJ, Keslacy S, Ploutz-Snyder LL. The metabolic costs of reciprocal supersets vs. traditional resistance exercise in young recreationally active adults. J Strength Cond Res. 2010;24(4):1043-51.

13. Robbins DW, Young WB, Behm DG, Payne WR. The effect of a complex agonist and antagonist resistance training protocol on volume load, power output, electromyographic responses, and efficiency. J Strength Cond Res. 2010;24(7):1782-9.

14. Bohannon RW. Knee extension torque during repeated knee extension-flexion reversals and separated knee extension-flexion dyads. PhysTher. 1985;65(7):1052-4.

15. Bohannon RW, Gibson DF, Larkin P. Effect of resisted knee flexion on knee extension torque PhysTher. 1986;66(8):1239-41.

16. Grabiner MD, Hawthorne DL. Conditions of isokinetic knee flexion that enhance isokinetic knee extension. Med Sci Sports Exerc. 1990;22(2):235-44.

17. Roy MA, Sylvestre M, Katch FI, Katch VL, Lagassé PP. Proprioceptive facilitation of muscle tension during unilateral and bilateral knee extension. Int J Sports Med. 1990;11(4):289-92.

18. Miller JP, Croce RV, Hutchins R. Reciprocal coactivation patterns of the medial and latera quadriceps and hamstrings during slow, medium and high speed isokinetic movements. J ElectromyogrKinesiol. 2000;10(4):233-9.

19. Jeon HS, Trimble MH, Brunt D, Robinson ME. Facilitation of quadriceps activation following a concentrically controlled knee flexion movement: the influence of transition rate. J Orthop Sports PhysTher. 2001;31(3):122-32.

20. Carregaro RL, Gentil P, Brown LE, Pinto RS, Bottaro M. Effects of antagonist pre-load on knee extensor isokinetic muscle performance. J Sports Sci. 2011;29(3):271-8.

21. Parcell AC, Sawyer RD, Tricoli VA, Chinevere TD. Minimum rest period for strength recovery during a common isokinetic testing protocol. Med Sci Sports Exerc. 2002;34(6):1018-22. 
22. Stumbo TA, Merriam S, Nies K, Smith A, Spurgeon D, Weir JP. The effect of hand-grip stabilization on isokinetic torque at the knee. J Strength Cond Res. 2001;15(3):372-7.

23. Merletti R. Standards for reporting EMG data. International Society of Electrophysiology and Kinesiology; 1999.

24. Soderberg GL, Knutson LM. A guide for use and interpretation of kinesiologicelectromyographic data. PhysTher. 2000;80(5):485-98.

25. Hermens HJ, Freriks B, Disselhorst-Klug C, Rau G. Development of recommendations for SEMG sensors and sensor placement procedures. J ElectromyogrKinesiol. 2000;10(5):361-74.

26. Basmajian JV, Deluca CJ. Muscles Alive. Their functions revealed by electromyography. $5^{\text {th }}$ ed. Baltimore: Williams \& Wilkins; 1985.

27. Dimitrov GV, Arabadzhiev TI, Mileva KN, Bowtell JL, Crichton N, Dimitrova NA.Muscle fatigue during dynamic contractions assessed by new spectral indices. Med Sci Sports Exerc. 2006;38(11):1971-9

28. Munn J, Herbert RD, Hancock MJ, Gandevia SC. Resistance training for strength: effect of number of sets and contraction speed. Med Sci Sports Exerc. 2005;37(9):1622-6.

29. Kelly SB, Brown LE, Coburn JW, Zinder SM, Gardner LM, Nguyen D. The effect of single versus multiple sets on strength. J Strength Cond Res. 2007;21(4):1003-6.

30. Galvão DA, Taaffe DR. Single- vs. multiple-set resistance training: recent developments in the controversy. J Strength Cond Res. 2004;18(3):660-7.

31. Rhea MR, Alvar BA, Burkett LN, Ball SD. A meta-analysis to determine the dose response for strength development. Med Sci Sports Exerc. 2003;35(3):456-64.

32. Humburg H, Baars H, Schröder J, Reer R, Braumann KM. 1-set vs. 3-set resistance training: a crossover study. J Strength Cond Res. 2007;21(2):578-82.

33. Tran QT, Docherty D. Dynamic training volume: a construct of both time under tension and volume load. J Sports Sci Med. 2006;5(4):707-13.

34. Coburn JW, Housh TJ, Malek MH, Weir JP, Cramer JT, Beck TW, et al. Neuromuscular responses to three days of velocity-specific isokinetic training. J Strength Cond Res. 2006;20(4):892-8

35. Hassani A, Patikas D, Bassa E, Hatzikotoulas K, Kellis E, Kotzamanidis C. Agonist and antagonis muscle activation during maximal and submaximal isokinetic fatigue tests of the knee extensors. J ElectromyogrKinesiol. 2006;16(6):661-8.

36. Moritani T, deVries HA. Neural factors versus hypertrophy in the time course of muscle strength gain. Am J Phys Med. 1979;58(3):115-30.

37. Solomonow M, Baratta R, Zhou BH, Shoji H, Bose W, Beck C, et al. The synergistic action of the anterior cruciate ligament and thigh muscles in maintaining joint stability. Am J Sports Med. 1987;15(3):207-13.

38. Baratta R, Solomonow M, Zhou H, Letson D, Chuinard R, D'Ambrosia R. Muscular coactivation. The role of the antagonist musculature in maintaining knee stability. Am J Sports Med. 1988;16(2):113-22.

39. Andersen LL, Magnusson SP, Nielsen M, Haleem J, Poulsen K, Aagaard P. Neuromuscular activation in conventional therapeutic exercises and heavy resistance exercises: implications for rehabilitation. PhysTher. 2006;86(5):683-97.

40. Poletto PR, Santos HH, Salvini TF, Coury HJCG, Hansson GA. Peak torque and knee kinematics during gait after eccentric isokinetic training of quadriceps in healthy subjects. Rev Bras Fisioter. 2008;12(4):331-7. 